\title{
Investigation of the electrooxidation of thymine on screen-printed carbon electrodes by hyphenation of electrochemistry and mass spec- trometry
}

Thomas Herl ${ }^{\dagger}$, Frank-Michael Matysik* ${ }^{*}{ }^{\dagger}$

'Faculty of Chemistry and Pharmacy, Institute of Analytical Chemistry, Chemo- and Biosensors, University of Regensburg, Universitätsstraße 31, 93053 Regensburg, Germany

*frank-michael.matysik@ chemie.uni-regensburg.de

Phone: +49-941-943-4547

Fax: +49-941-943-4991

The Supporting Information contains:

- $\quad$ Figure S1 (CID spectra of oxidation products $\mathbf{1 a}$ and $\mathbf{1 b}$ )

- $\quad$ Figure S2 (CID spectra of oxidation products $\mathbf{2 a}$ and $\mathbf{2 b}$ )

- $\quad$ Figure S3 (fit data for the calculation of the $\mathrm{pK}_{\mathrm{a}}$ of thymine)

- Figure $\mathrm{S} 4$ (fit data for the calculation of the $\mathrm{pK}_{\mathrm{a}}$ values of 1a)

- $\quad$ Figure S5 (fit data for the calculation of the $\mathrm{pK}_{\mathrm{a}}$ values of $\mathbf{1 b}$ ) 

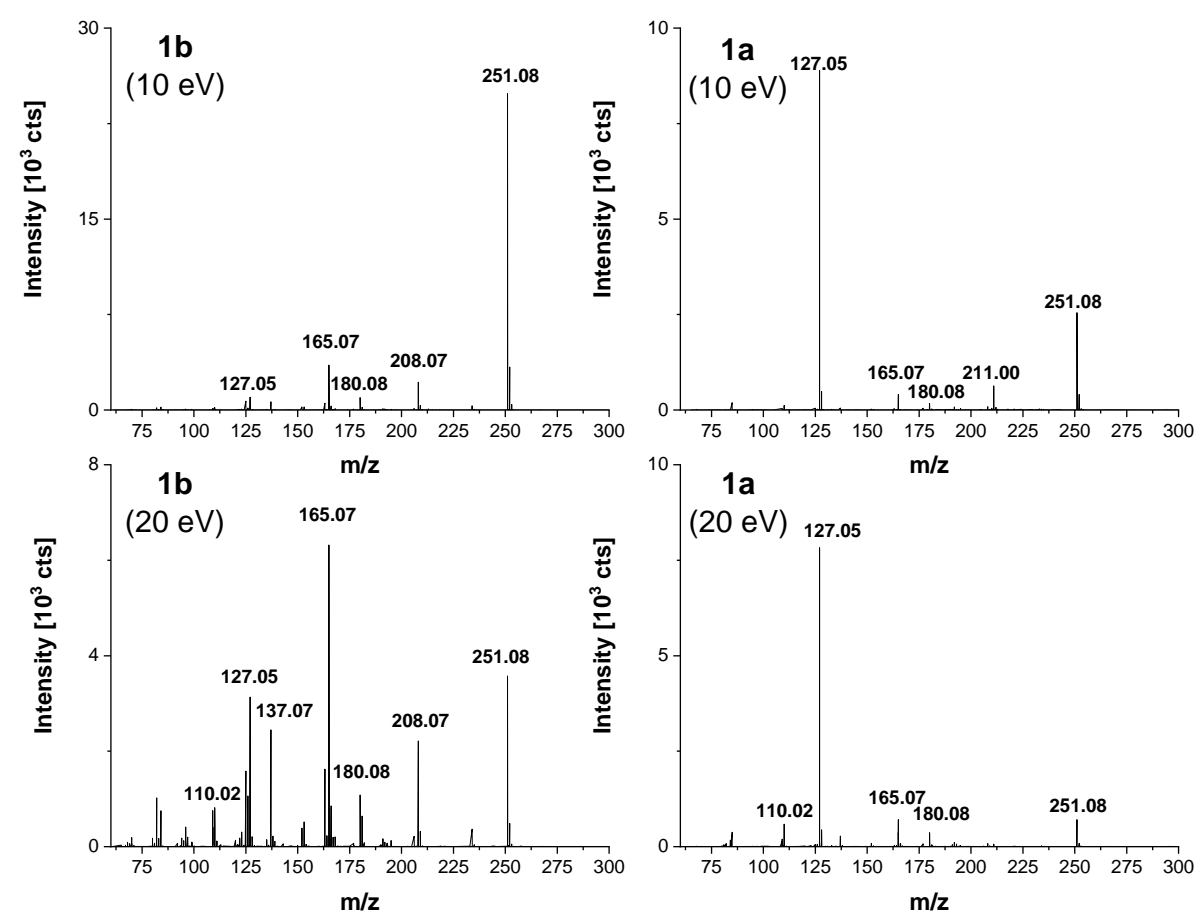

Figure S1. CID spectra of $\mathbf{1 b}$ at collision energies of $10 \mathrm{eV}$ and $20 \mathrm{eV}$ (left column) and CID spectra of $\mathbf{1 a}$ at collision energies of $10 \mathrm{eV}$ and $20 \mathrm{eV}$ (right column).
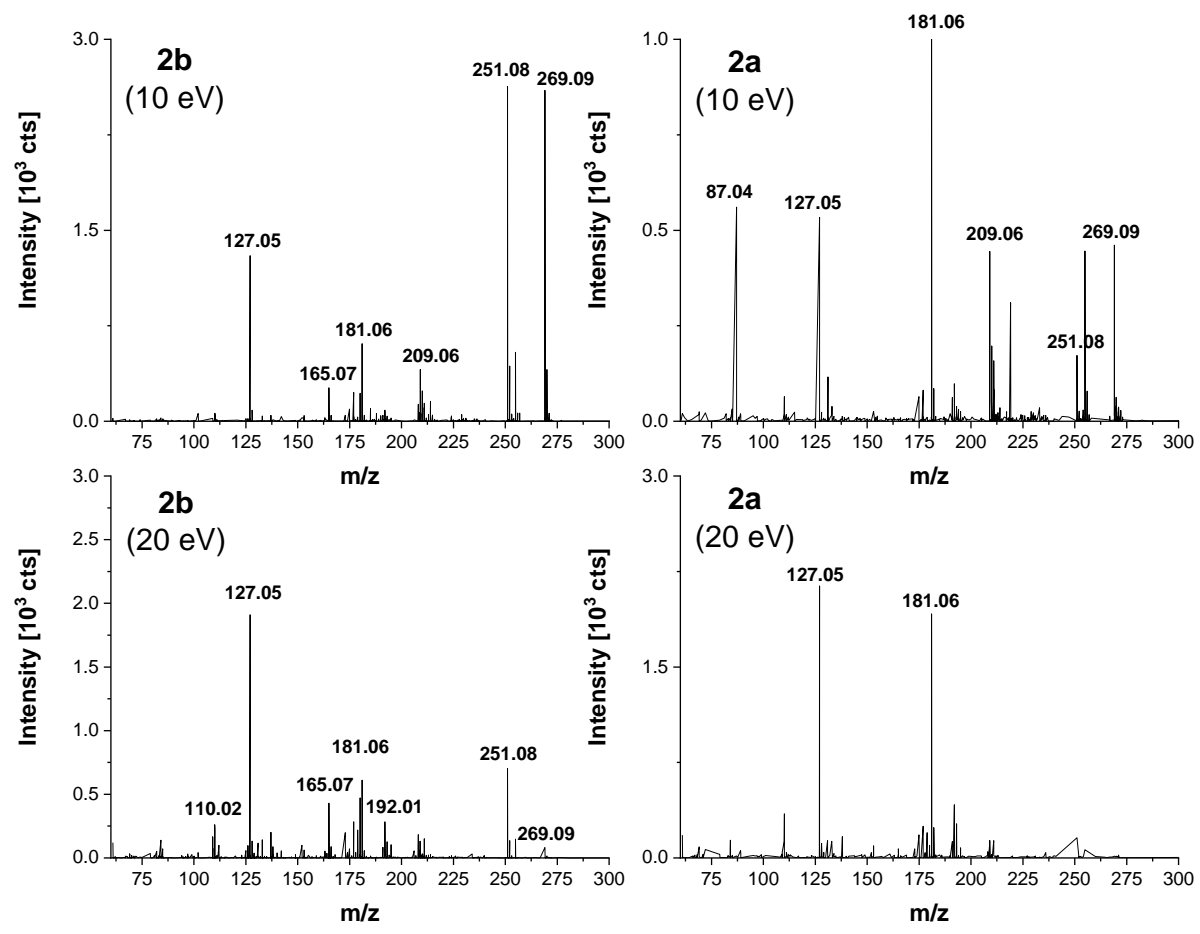

Figure S2. CID spectra of $\mathbf{2 b}$ at collision energies of $10 \mathrm{eV}$ and $20 \mathrm{eV}$ (left column) and CID spectra of $\mathbf{2 a}$ at collision energies of $10 \mathrm{eV}$ and $20 \mathrm{eV}$ (right column). 


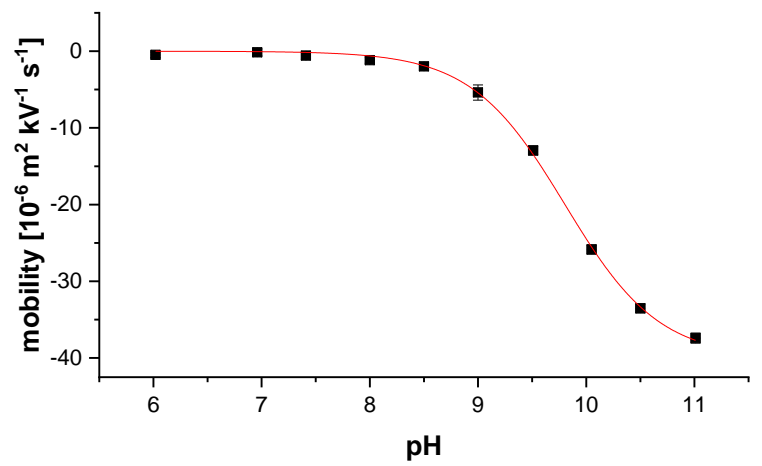

Figure S3. Fit data for the calculation of the $\mathrm{pK}_{\mathrm{a}}$ value of thymine. Fit by $\mathrm{Me}_{\mathrm{e}}=\mathrm{M}_{\mathrm{a}} /\left(10^{(\mathrm{pKa}-\mathrm{pH})}+1\right)$ with $\mathrm{Ma}_{\mathrm{a}}=-4.01 \cdot 10^{-5} \pm$ $0.06 \cdot 10^{-5} \mathrm{~m}^{2} \mathrm{kV}^{-1} \mathrm{~s}^{-1}$ and $\mathrm{pK}_{\mathrm{a}} 9.80 \pm 0.02$.
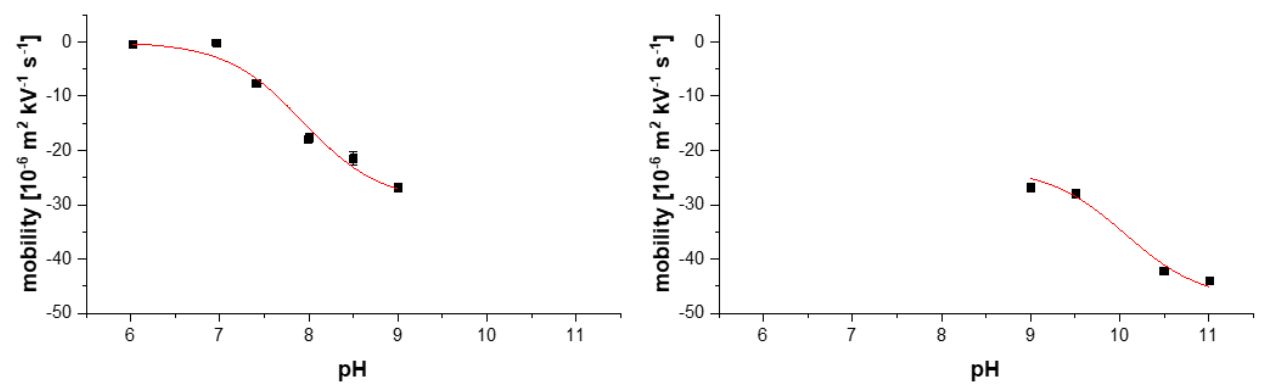

Figure S4. Fit data for the calculation of the $\mathrm{pK}_{\mathrm{a}}$ values of $1 \mathrm{a}$. Fit by $\mathrm{M}_{\mathrm{e}}=\mathrm{M}_{\mathrm{a}} /\left(10^{(\mathrm{pKa}-\mathrm{pH})}+1\right)$ with $\mathrm{M}_{\mathrm{a}}=-2.9 \cdot 10^{-5} \pm 0.3 \cdot 10^{-5} \mathrm{~m}^{2} \mathrm{kV}^{-1} \mathrm{~s}^{-1}$ and $\mathrm{pK}_{\mathrm{a}} 7.9 \pm 0.1$ (left) and $\mathrm{M}_{\mathrm{e}}=\mathrm{M}_{\mathrm{a}} /\left(10^{(\mathrm{pKa}-\mathrm{pH})}+1\right)+\mathrm{C}$ with $\mathrm{M}_{\mathrm{a}}=-2.4 \cdot 10^{-5} \pm 0.3 \cdot 10^{-5} \mathrm{~m}^{2} \mathrm{kV}^{-1} \mathrm{~s}^{-1}, \mathrm{pK}_{\mathrm{a}} 10.1 \pm 0.4$ and $\mathrm{C}-2.3 \cdot 10^{-5} \pm$ $0.4 \cdot 10^{-5} \mathrm{~m}^{2} \mathrm{kV}^{-1} \mathrm{~s}^{-1}$ (right).
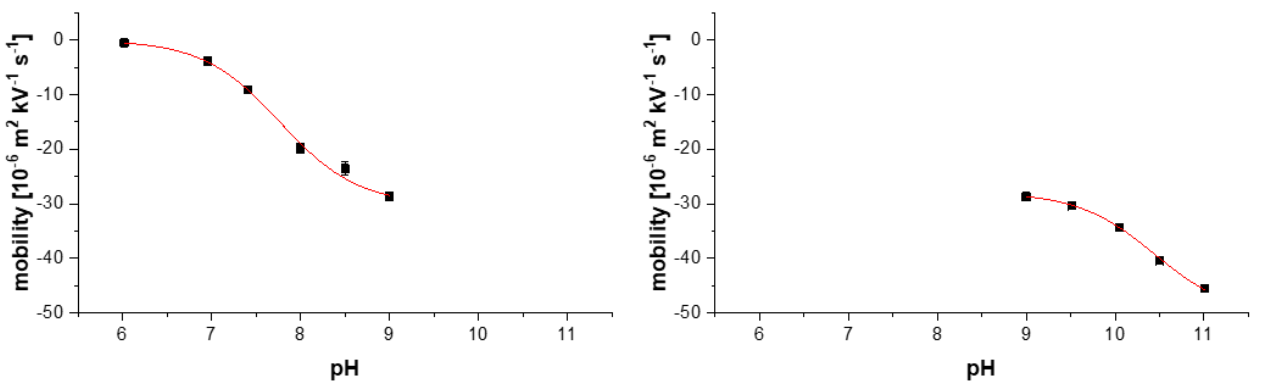

Figure S5. Fit data for the calculation of the $\mathrm{pK}_{\mathrm{a}}$ values of $\mathbf{1 b}$. Fit by $\mathrm{Me}_{\mathrm{e}}=\mathrm{M}_{\mathrm{a}} /\left(10^{(\mathrm{pKa}-\mathrm{pH})}+1\right)$ with $\mathrm{M}_{\mathrm{a}}=-3.01 \cdot 10^{-5} \pm 0.08 \cdot 10^{-5} \mathrm{~m}^{2} \mathrm{kV}^{-1} \mathrm{~s}^{-1}$ and $\mathrm{pK}_{\mathrm{a}} 7.77 \pm 0.0 .03$ (left) and $\mathrm{M}_{\mathrm{e}}=\mathrm{M}_{\mathrm{a}} /\left(10^{(\mathrm{pKa}-\mathrm{pH})}+1\right)+\mathrm{C}$ with $\mathrm{M}_{\mathrm{a}}=-2.3 \cdot 10^{-5} \pm 0.1 \cdot 10^{-5} \mathrm{~m}^{2} \mathrm{kV}^{-1} \mathrm{~s}^{-1}, \mathrm{pK}_{\mathrm{a}} 10.45 \pm 0.06$ and C $-2.79 \cdot 10^{-5} \pm$ $0.04 \cdot 10^{-5} \mathrm{~m}^{2} \mathrm{kV}^{-1} \mathrm{~s}^{-1}$ (right). 